\title{
Estandarización de un método citoquímico con microscopía electrónica para detectar actividad enzimática en células completas
}

\author{
María L. Caldas ${ }^{1}$, Moisés Wasserman ${ }^{2}$
}

\begin{abstract}
Resumen
Mediante métodos de citoquímica ultraestructural, se localizó la actividad de ATPasa de $\mathrm{Ca}^{2+}$ en membranas de eritrocitos humanos tanto normales como invadidos por Plasmodium falciparum.

Para detectar la actividad de esta ATPasa se utilizó un método directo de precipitación con metales pesados, en donde el plomo o el cerio forman un precipitado electrodenso con el fosfato libre, producto de hidrólisis de la enzima, sobre la supeficie de dichas membranas.

Este método utiliza un medio de incubación que contiene todos los elementos necesarios para que se desarrolle la reacción enzimática e incluye herramientas bioquímicas, tales como, inhibidores tanto de la ATPasa como de calmodulina que permiten confirmar la especificidad de la actividad de ATPasa de $\mathrm{Ca}^{2+}$ en un estudio bioquímico con citoquímica ultraestructural.
\end{abstract}

\section{Sumary}

$\mathrm{Ca}^{2+}$-ATPase activity in human erythrocyte membranes was localized by ultrastructural cytochemistry. Normal and Plasmodium falciparum infected erythrocytes were studied. The method basically consisted of local precipitation of heavy metal ions such $\mathrm{as}^{\mathrm{Pb}}{ }^{2+}$ and $\mathrm{Ce}^{3+}$ by the phosphate resulting from ATP hydrolysis. Thick fixed samples were incubated in a medium containing the necessary elements for the desired enzyme reaction. $\mathrm{Ca}^{2+}$ ATPase and calmodulin inhibitors were used to improve definition of the specificity of the enzyme activity under study.

Considerando las evidencias que demuestran el papel determinante del calcio para el desarrollo del parásito a saber: el requerimiento de este ion para el proceso de invasión de Plasmodium falciparum a los eritrocitos humanos, el incremento significativo de este catión en los eri- trocitos infectados y la necesidad de mantener altas concentraciones de calcio para el desarrollo del parásito en la vacuola parasitófora $(1,2)$, es importante realizar trabajos que contribuyan a explicar los mecanismos involucrados en el transporte de calcio durante la invasión y el

Grupo de Bioquímica, Instituto Nacional de Salud, Santafé de Bogotá, Colombia.

2 Coordinador del Grupo de Bioquímica, Profesor asociado, Facultad de Ciencias, Universidad Nacional de Colombia; Instituto Nacional de Salud, Santafé de Bogotá, Colombia. 
desarrollo asexual. La ubicación de bombas catiónicas como la ATPasa de calcio sería uno de ellos; por tal razón surgió la necesidad de utilizar un método que permitiera determinar la presencia de esta enzima de membrana, su actividad y su distribución en los complejos de membrana encontrados en células completas de eritrocitos humanos invadidos por Plasmodium falciparum.

La bomba transportadora de calcio de la membrana plasmática es una proteína integral de membrana de $140 \mathrm{KD}$ que cataliza la hidrólisis de ATP para expulsar calcio hacia el exterior de la célula en contra de un gradiente de concentración y es regulada por la concentración de $\mathrm{Ca}^{2+}, \mathrm{Mg}^{2+}$, ATP y calmodulina $(3,4)$.

La detección de actividades de enzimas hidrolíticas en microscopía electrónica (ME) se basan en el uso de medios de incubación en los que se precipita el grupo saliente (fosfato inorgánico en
ATPasa) con metales pesados como plomo, cerio, bario o cobre. Los iones de fosfato liberados como producto de hidrólisis son atrapados en su sitio de formación por agentes de captura como plomo o cerio. Los precipitados son sales insolubles y electrodensos como fosfato de plomo o cerio, productos finales de reacción (Fig. 1) $(5,6)$.

Para detectar la actividad de ATPasa de $\mathrm{Ca}^{2+}$ presente en la membrana de los eritrocitos se utilizó un método directo descrito por Ando en 1981, en el cual en un solo paso de reacción se activa la enzima y se produce la reacción citoquímica misma (precipitación), teniendo en cuenta $\mathrm{pH}$, temperatura, solubilidad y concentración del sustrato.

Este método intenta solucionar importantes problemas de citoquímica ultraestructural como son la difusión del producto final de reacción, insolubilidad del agente de captura y la formación

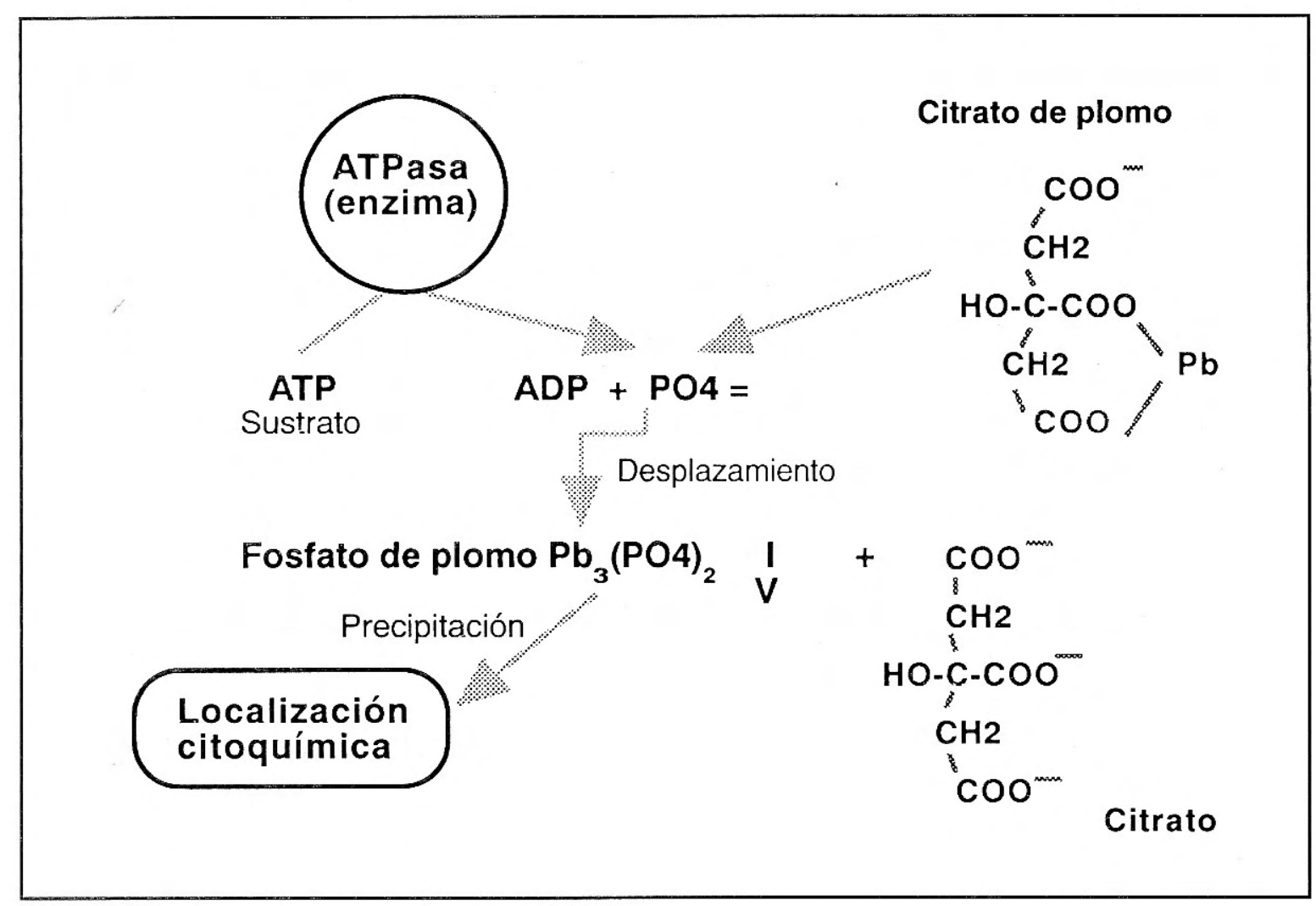

Figura 1. Fundamento del método citoquímico 
inespecífica de precipitados electrodensos, a través de una reacción directa y un $\mathrm{pH}$ inicialmente alcalino que equilibra la acidificación del medio en el desplazamiento de las sales.

\section{Materiales y métodos}

\section{Obtención y manejo inicial de muestras}

Se utilizaron muetras de $1 \mathrm{~mL}$, tanto de eritrocitos humanos normales $\mathrm{O}(+)$ como de eritrocitos invadidos con Plasmodium falciparum, cepa colombiana FCB2 cultivada según el método de Trager y Jensen (7) en el laboratorio de bioquímica del INS. El cultivo se sincronizó según el método estandarizado en el laboratorio (8) para obtener tanto formas jóvenes $\mathrm{o}$ anillos y formas maduras del parásito (9). Cada una de estas muestras se enjuagó en solución amortiguadora Hepes (HBS) pH 7.4 y luego se sometió a un tratamiento de prefijación colocándolas en una mezcla de paraformaldehído (PFA) $2 \%$ y glutaraldehído (GA) $0.25 \%$ durante 20 minutos a $4^{\circ} \mathrm{C}$ y se lavó finalmente luego con la solución amortiguadora. Paralelamente se evaluó el efecto de la fijación sobre la actividad enzimática, utilizando mezcla de fijadores de PFA $1 \%$ y GA $0.125 \%$, sin prefijación, con tiempos de fijación de 15 minutos y con GA al $0.5 \%$.

\section{Activación de la enzima y localización ultra- estructural}

Después de prefijadas las muestras, se colocaron en un medio de incubación compuesto de:

$\begin{array}{lr}\text { Solución amortiguadora de glicina/ } / \mathrm{NaOH}, \mathrm{pH} 9.0 & 250 \mathrm{mM} \\ \text { Citrato de plomo } & 2 \mathrm{mM} \\ \mathrm{CaCl}_{2} & 10 \mathrm{mM} \\ \mathrm{NaCl} & 10 \mathrm{mM} \\ \mathrm{MgCl}_{2} & 5 \mathrm{mM} \\ \mathrm{KCl} & 10 \mathrm{mM} \\ \text { ATP } & 3 \mathrm{mM} \\ \text { Levamisol (inhibidor de fosfatasas) } & 10 \mathrm{mM}\end{array}$

Como control negativo de la reación, se utilizó este medio al cual se le adicionó los siguientes inhibidores de ATPasa:

Vanadato de amonio (inhibidor general)

Ouabaína (inhibidor de ATPasa $\mathrm{Na}^{+} / \mathrm{K}^{+}$)

EGTA (quelante de calcio)
La activación de la enzima en este medio se realizó a $37^{\circ} \mathrm{C}$ durante 30 minutos. Para detener la reacción enzimática se colocaron las muestras sobre hielo por 5 minutos y se lavaron en solución amortiguadora de cacodilato de sodio $0.1 \mathrm{M}, \mathrm{pH}$ 7,2 . Posteriormente se evaluó el efecto del ionóforo específico de calcio A23187 sobre la actividad enzimática adicionandolo al medio de incubación en una concentración final de $10 \mu \mathrm{M}$.

Después de haberse producido la reacción enzimática, se procesaron las muestras para ME convencional: fijación con GA $2 \%$ y OsO $1 \%$, coloración en bloque con acetato de uranilo $1 \%$, deshidratación e inclusión en resinas epóxicas (Epón-Araldita). La observación de los cortes ultrafinos se hizo en un microscopio electrónico Zeiss E9.

\section{Permeabilización de células completas y ac- tividad enzimática}

Se evaluó el efecto de detergentes sobre la actividad enzimática adicionando a los medios de incubación deoxicolato de sodio 0.1 y $0.04 \%$ y NP40 0.1 y $0.003 \%$ respectivamente, y verificando su efecto sobre las células.

Paralelamente se evaluó el efecto de la alameticina, péptido formador de canales en membranas, para la conservación de células completas. Estas se colocaron en medios de incubación que contenían alameticina a concentraciones de 5 , $10,15,20,25,50$ y $80 \mu \mathrm{g} / \mathrm{ml}$. Luego de activar la enzima en estas condiciones, se procesaron las muestras para ME.

\section{Comparación de dos métodos citoquímicos}

Se evaluaron dos métodos que utilizan como agentes de captura citrato de plomo y cloruro de cerio y como producto final de reacción obtienen fosfato de plomo y cerio respectivamente. EI medio de incubación que utilizaba plomo fue descrito anteriormente y el de cerio contiene lo siguiente:

$\begin{array}{lr}\text { Solución amortiguadora tris-maleato } & 70 \mathrm{mM} \\ \mathrm{CeCl}_{3} & 2 \mathrm{mM} \\ \mathrm{CaCl}_{2} & 0.15 \mathrm{mM} \\ \mathrm{MgCl}_{2} & 0.10 \mathrm{mM} \\ \mathrm{EGTA} & 0.10 \mathrm{mM} \\ \text { ATP } & 3 \mathrm{mM} \\ \text { El pH del medio fue de 7.4, y además se adicionaron al medio: } \\ \text { lonóforoA23187 } & 10 \mu \mathrm{M} \\ \text { Alameticina } & 50 \mu \mathrm{g} / \mathrm{mL}\end{array}$


La incubación de la muestras en este medio se realizó a $25^{\circ}$ y $37^{\circ} \mathrm{C}$ durante 30 minutos sin la adición de ATP y luego por 60 minutos con el medio completo. Luego del ensayo de activación las muestras se procesaron para ME.

\section{Caracterización de la actividad de ATPasa de $\mathrm{Ca}^{2+}$}

La actividad deATPasa de $\mathrm{Ca}^{2+}$ fue caracterizada mediante el uso de inhibidores de dicha enzima, de otras ATPasas y de calmodulina, la proteína reguladora de la actividad de ATPasa. Para determinar la actividad específica de ATPasa de $\mathrm{Ca}^{2+}$ se adicionó al medio de incubación ouabaína $10 \mathrm{mM}$ y $\sin \mathrm{KCl}$ para inhibir la ATPasa de $\mathrm{Na}^{+} / \mathrm{K}^{+}$.

Para verificar otras actividades de ATPasa como la de $\mathrm{Na}^{+} / \mathrm{K}^{+}$y $\mathrm{Mg}^{2+}$ se adicionó al medio de activáción un quelante de calcio, EGTA $20 \mathrm{mM}$ y $\sin \mathrm{CaCl}_{2}$ con lo cual se inhibe la bomba de calcio y se da la posibilidad de observar diferencialmente otras actividades.

Para determinar actividad específica de ATPasa de $\mathrm{Mg}^{2+}$ se adicionó al medio de incubación los inhibidores de las otras dos bombas, ouabaína y EGTA.

Otra forma de caracterizar la actividad de esta enzima se realizó utilizando inhibidores de calmodulina como : trifluoperazina (TFP) 300 $\mu \mathrm{M}$, W7 $300 \mu \mathrm{M}$, calmidazolium (CD) $300 \mu \mathrm{M}$ y un sustituyente isomórfico de calcio: cloruro de lantano $\left(\mathrm{LaCl}_{3}\right) 100 \mu \mathrm{M}$. Las muestras se colocaron en los medios de incubación que contenían estos inhibidores y luego se procesaron para ME.

\section{Resultados}

La actividad de ATPasa de $\mathrm{Ca}^{2+}$ se expresó mediante la formación de fosfato de plomo como producto de la reacción, el cual se distribuyó

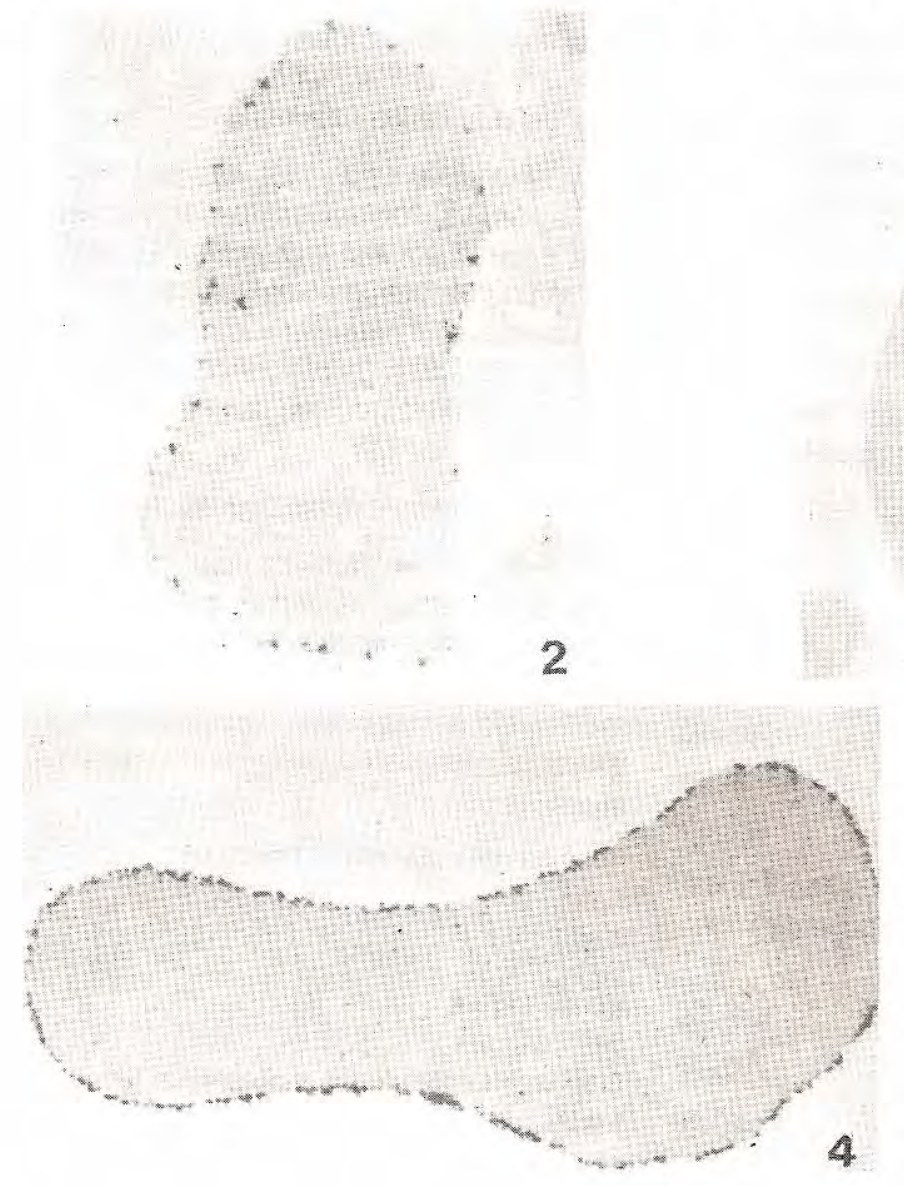

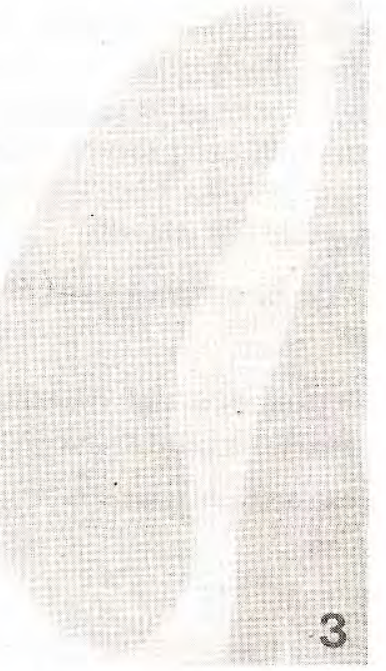

Figura 2. Actividad basal de ATPasa de $\mathrm{Ca}^{2+}$ en la membrana plasmática de un eritrocito sin invadir $45000 \mathrm{X}$.

Figura 3. Inhibición de actividad de ATPasa por vanadato 500 um, ouabaína $10 \mathrm{~mm}$ EGTA $20 \mathrm{~mm}$ (control negativo) 21000X.

Figura 4. Efecto del ionóforo A23187 sobre la actividad de ATPasa en eritrocitos sin invadir 18000X. 
como precipitado electrodenso sobre toda la superficie de la membrana del eritrocito (Fig. 2). En el control negativo se observa una completa inhibición de la actividad de ATPasa por acción de los inhibidores: vanadato $5 \mathrm{mM}$, ouabaína 10 mM y EGTA 20 mM (Fig. 3).

\section{Concentración de calcio}

Al aumentar el contenido intracelular de calcio en el eritrocito con el uso del ionóforo A23187, en la figura 4 se observa un aumento notable de la actividad de ATPasa de $\mathrm{Ca}^{2+}$.

\section{Fijación}

En la evaluación del efecto de fijación sobre la actividad de ATPasa se obtuvieron las condiciones óptimas que permitieron una buena preservación morfológica sin inactivar la enzima. Como ensayo control se utilizaron las concentraciones mínimas del fijador de Karnovsdky que detectaron la actividad de la bomba; en la figura 5 se observa este resultado con una preservación de la célula roja y una actividad de ATPasa óptimas, distribuídas uniformemente a lo largo de toda la superficie de la membrana misma. Al modificar la concentración de los fijadores, PFA a $1 \%$ y Ga a $0.125-\%$, se observa que hay desprendimiento de la membrana celular y sobre ésta una marcada especificidad de la localización del precipitado electrodenso (Fig. 6). Cuando los eritrocitos se colocan directamente al medio de activación sin ser prefijados se evidencia una pobre definición de estructuras membranales y mala preservación del material celular pero se

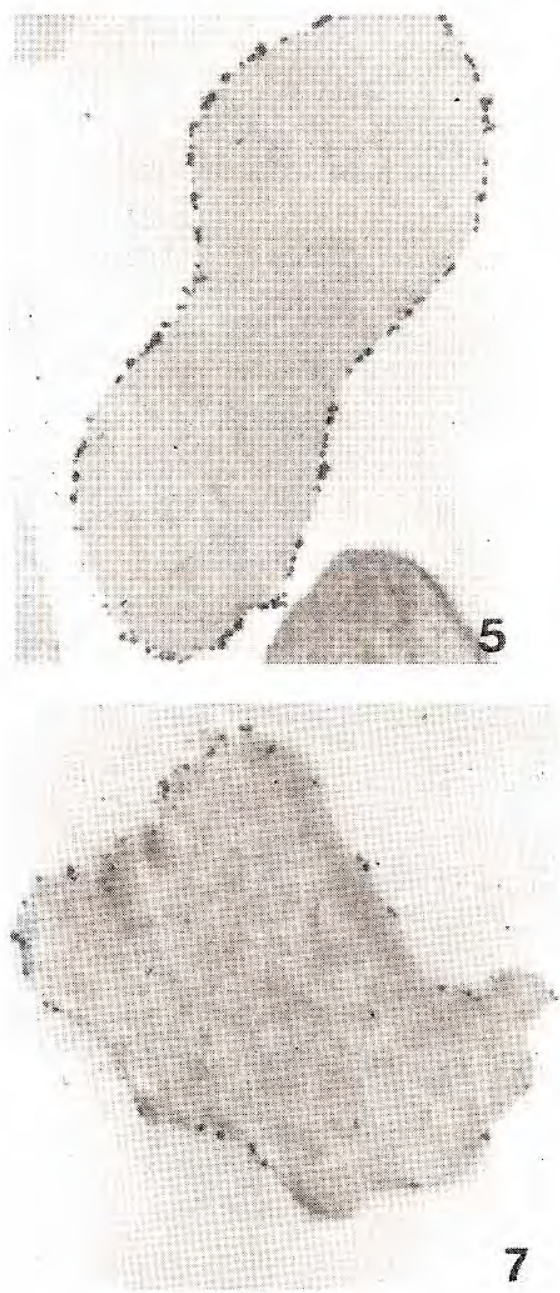

7

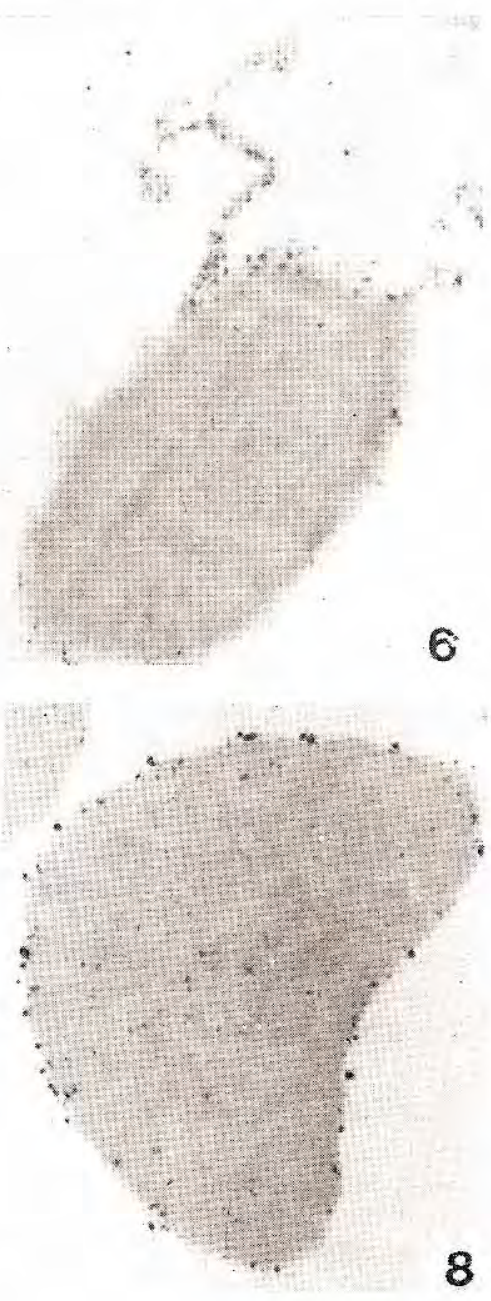

Figura 5. Actividad de ATPasa de $\mathrm{Ca}^{2+}$ en la membrana plasmática de un eritrocito sin invadir: paraformaldehído $1 \%$ y glutaradehído $0.25 \%$, (control positivo) $34000 \mathrm{X}$.

Figura 6. Acción de fijadores sobre la actividad de ATPasa en eritrocitos $\sin$ invadir: paraformaldehído $1 \%$ y glutaraldehído $0.125 \%, 18000$ X.

Figura 7. Actividad de ATPasa en eritrocitos no invadidos sin tratamiento de prefijación 34000X.

Figura 8. Acción de fijadores sobre la actividad de ATPasa en oritrocitos sin invadir: glutaraldehído $0.5 \% 32000 \mathrm{X}$. 
conserva muy bien la actividad de la enzima (Fig. 7). Los ensayos en que se disminuyó el tiempo y se modificó la concentración del GA no se detectó diferencia respecto a los resultados anteriores (Fig. 8)

\section{Permeabilización}

Para la conservación de las células completas y obtención de actividad de ATPasa, los detergentes aniónicos deoxicolato de sodio y NP40 al 0.1\%

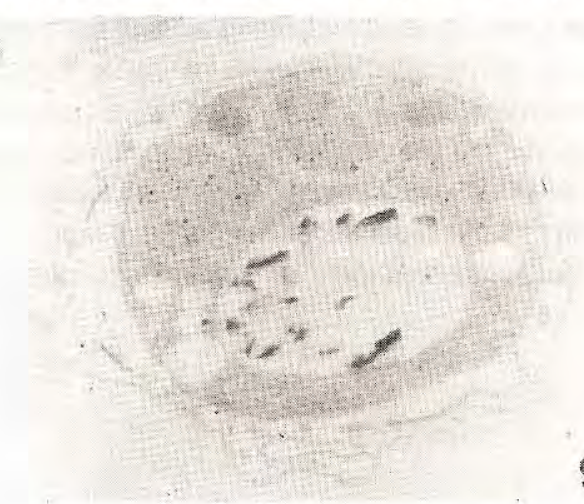

9

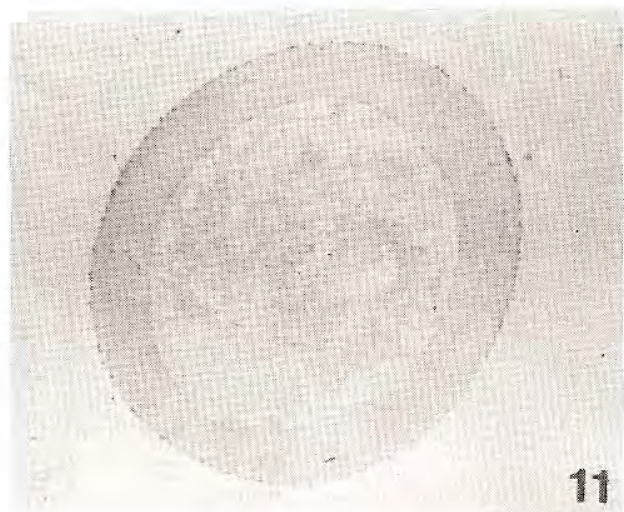

Figura 9 y 10. Acción de detergentes sobre la actividad de ATPasa en eritrocitos invadidos: deoxicolato de sodio y NP40 $0.1 \%$ respectivamente 19200X y 20400X.

Figura 11 y 12. Acción de detergentes sobre la actividad de ATPasa en eritrocitos invadidos: deoxicolato de sodio $0.04 \%$ y NP40 $0.003 \%$ respectivamente $19200 \mathrm{X}$ y $18000 \mathrm{X}$.

Figura 13. Efecto de alameticina $50 \mathrm{~m} \mu / \mathrm{mL}$ sobre la actividad de ATPasa en eritrocitos invadidos. Detalle de la actividad en membrana de la vacuola parasitófora (MVP). Las flechas señalan ausencia de actividad en las membranas del parásito 15000X. produjeron desprendimiento de la membrana del eritrocito y un alto grado de lisis celular (Figs. 9 y $10)$. Las más altas concentraciones probadas que no produjeron lisis fueron $0.04 \%$ y $0.003 \%$ para estos detergentes respectivamente (Figs. 11 y 12).

La utilidad del péptido alameticina para aumentar la permeabilidad de ATP y de otros reactivos del medio de activación se observa en la figura 13 , en
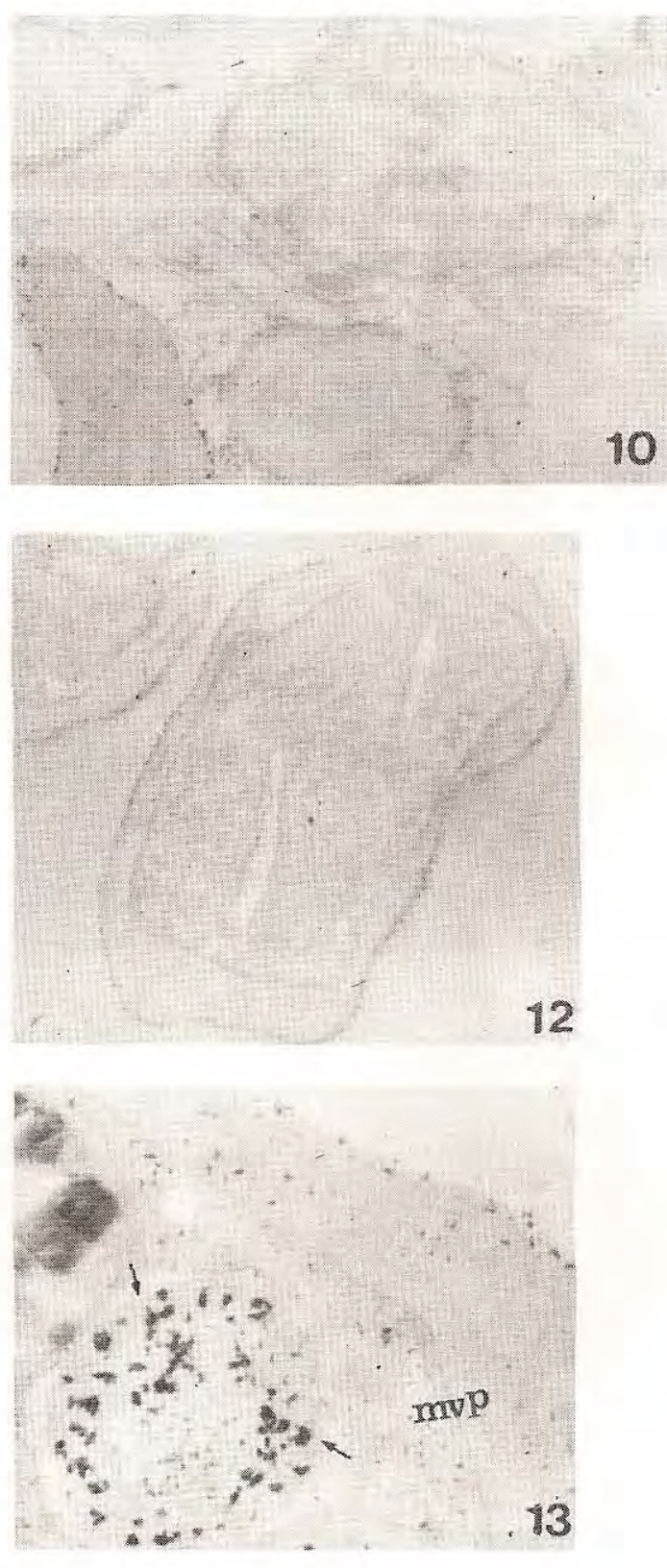
la cual a $50 \mu \mathrm{g} / \mathrm{mL}$ permitió detección dè actividad en los complejos membranales internos de la célula invadida.

\section{Comparación de dos métodos citoquímicos}

Basados en la obtención de fosfato de plomo (Fig. 14) o fosfato de cerio (Fig.15), se eligió el plomo como mejor agente de captura de la reacción, dada la uniformidad y definición de la localización del precipitado.

\section{Uso de inhibidores}

La caracterización de la actividad de ATPasa de calcio mediante la acción diferencial de inhibidores se observa en las figuras 16,17 y 18 , en las cuales se determina específicamente la actividad de ATPasa de $\mathrm{Ca}^{2+}$ y no se detecta influencia de otras ATPasas tales como la de $\mathrm{Na}^{+} / \mathrm{K}^{+}$y $\mathrm{Mg}^{2+}$ respectivamente con el método utilizado.

El uso de inhibidores de calmodulina permitió detectar cambios en la actividad de ATPasa,
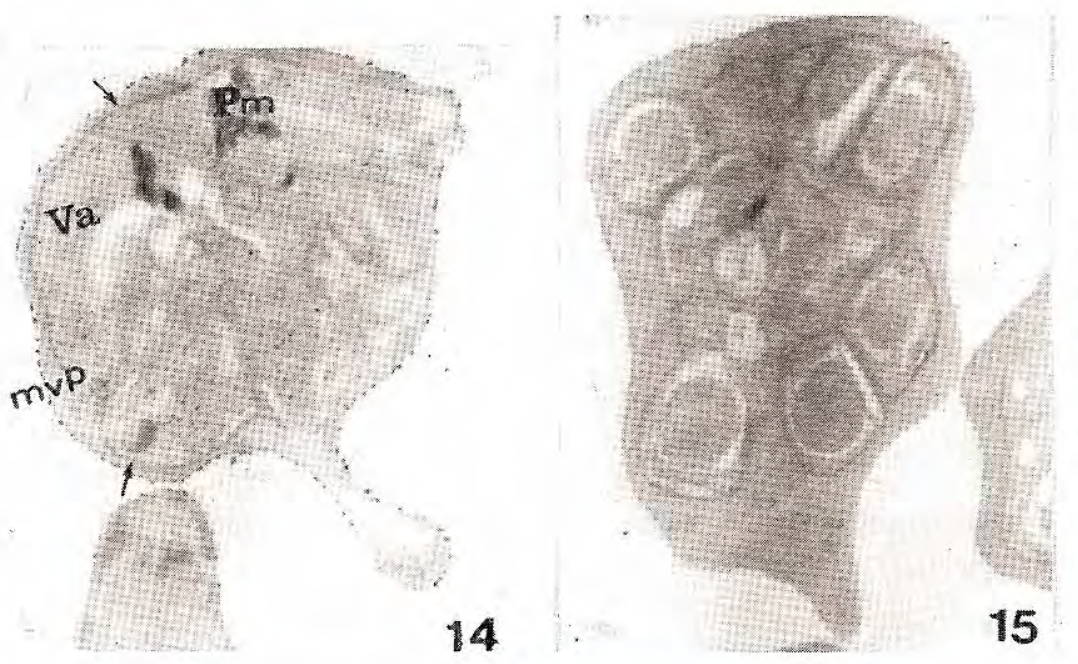

Figura 14. Método citoquímico de fosfato de plomo en eritrocitos invadidos con trofozoítos de 3436 horas. Las flechas señalan disminución de actividad en MVP. Vacuola alimenticia (Va), Pigmento malárico (Pm) 78000X.

Figura 15. Método citoquímico de fosfato de cerio en eritrocitos invadidos con esquizontes de más de 42 horas $18000 X$.
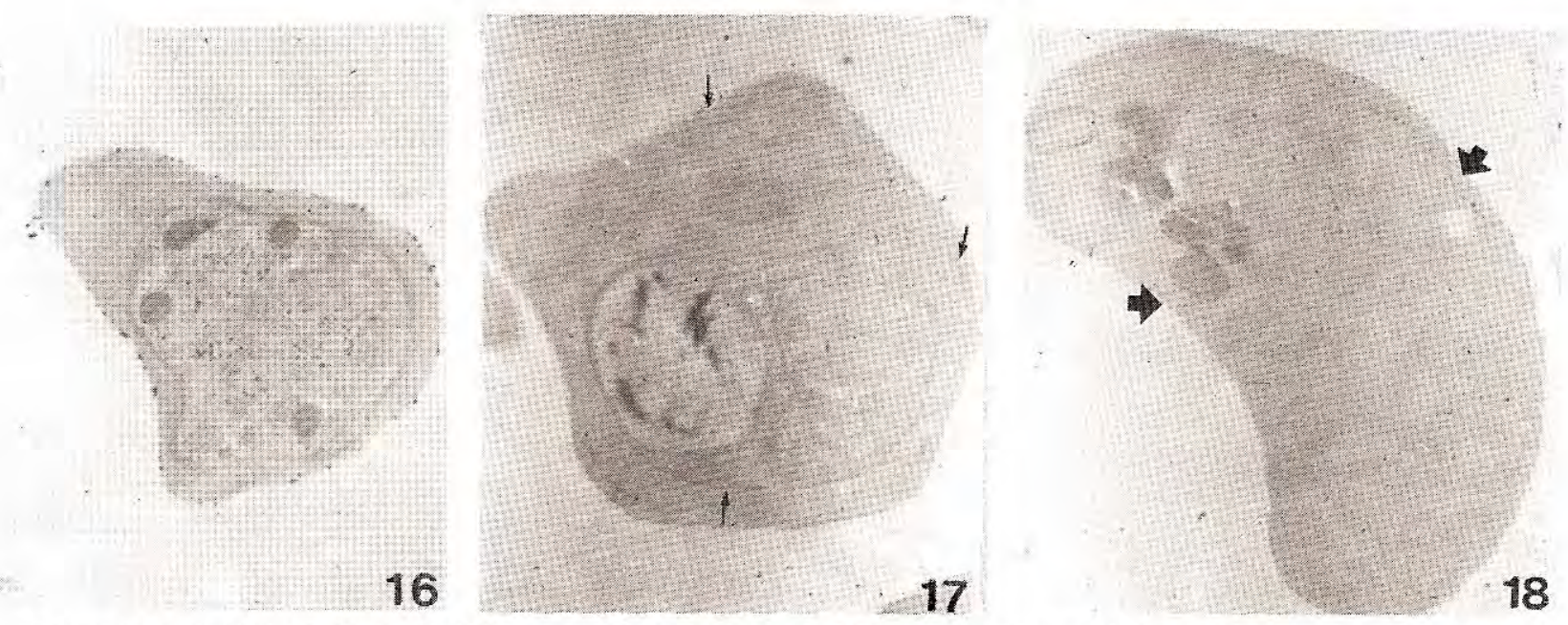

Figura 16. Actividad específica de ATPasa de $\mathrm{Ca}^{2+}$ obtenida mediante la acción diferencial de inhibidores, en un eritrocito invadido con trofozoítos de 34-36 horas 19200X.

Figura 17. Actividad de ATPasa de $\mathrm{Na}^{+} / \mathrm{K}^{+}$en un eritrocito invadido con trofozoítos de $34-36$ horas. Las flechas indican ausencia de actividad con el método utilizado 18000X.

Figura 18. Actividad de ATPasa diferente a la de $\mathrm{Ca}^{2+}$ y Na $\mathrm{Na}^{+} / \mathrm{K}^{+}$en un eritrocito invadido con anillos de 16-18 horas. Las flechas indican ausencia de actividad con el método utilizado $18000 \mathrm{X}$. 
co-mo se observa en la figura 19 y 20 donde es dismi-nuída por acción de TFP y CD respectivamente, dejando ver en esta última, señal de actividad de algunas fosfatasas internas. En la figura 21 se ob-serva absoluta inhibición de activad de ATPasa de calcio por el cloruro de lantano.

Condiciones óptimas de la estandarización

\begin{tabular}{ll}
\hline Condiciones & \multicolumn{1}{c}{ Descripción } \\
\hline Prefijación & $\begin{array}{l}\text { Mezcla de PFA } 2 \% \text { y GA } 0.25 \% \\
\text { por } 20 \text { minutos a } 4^{\circ} \mathrm{C} .\end{array}$ \\
Activación & $\begin{array}{l}\text { Medio de incubación descrito por } \\
\text { Ando, } 1981 .\end{array}$ \\
Concentración $\mathrm{Ca}^{2+}$ & $\begin{array}{l}\text { Ionóforo A23187 } 10 \mu \mathrm{M} . \\
\text { Permeabilidad }\end{array}$ \\
Inhibidores y caracterización diferencial: \\
ATPasa Ca ${ }^{2+}$ & $\begin{array}{l}\text { EGTA } 20 \mathrm{mM}, \mathrm{Vanadato} 0.5 \mathrm{mM} \\
\text { y sin CaCl }\end{array}$ \\
ATPasa $\mathrm{Na}^{+} / \mathrm{K}^{+}$ & Ouabaína $10 \mathrm{mM}$ y $\operatorname{sin~} \mathrm{KCl}$. \\
ATPasa $\mathrm{Mg}^{2+}$ & Ouabaína $10 \mathrm{mM}$ y EGTA $20 \mathrm{mM}$. \\
\hline
\end{tabular}

\section{Discusión}

La actividad de ATPasa de $\mathrm{Ca}^{2+}$ fue detectada con un método citoquímico que permite el estudio ul- traestructural de células completas por microscopía electrónica. Las principales ventajas de este método son la obtención de señal de actividad de ATPasa en un solo paso de reacción y el uso de $\mathrm{pH}$ alcalino que asegura la completa solubilidad del plomo, evitando la aparición de precipitados electrodensos inespecíficos que podrían confundirse con el producto real. Además es importante la estabilidad del medio de activación de la enzima, el desplazamiento mínimo del producto final de reacción y la utilidad que este método proporciona en un microscopio electrónico convencional $(5,10)$.

La sensibilidad del método no fue la requerida para visualizar la actividad basal de la enzima bajo las condiciones experimentales, por lo cual fue necesario incrementar la concentración intracelular de calcio con el ionóforo A23187 en cuyo resultado se evidencia la respuesta de la enzima a esta variación $(4,11)$.

A partir de una concentración intracelular de calcio de $50 \mu \mathrm{M}$ y $5 \mu \mathrm{M}$ de $\mathrm{A} 23187$ (12), sumado con las reacciones de membrana por estrés de fijación $(10,13)$, se pueden ocasionar cambios morfológicos. Pero las condiciones de fijación
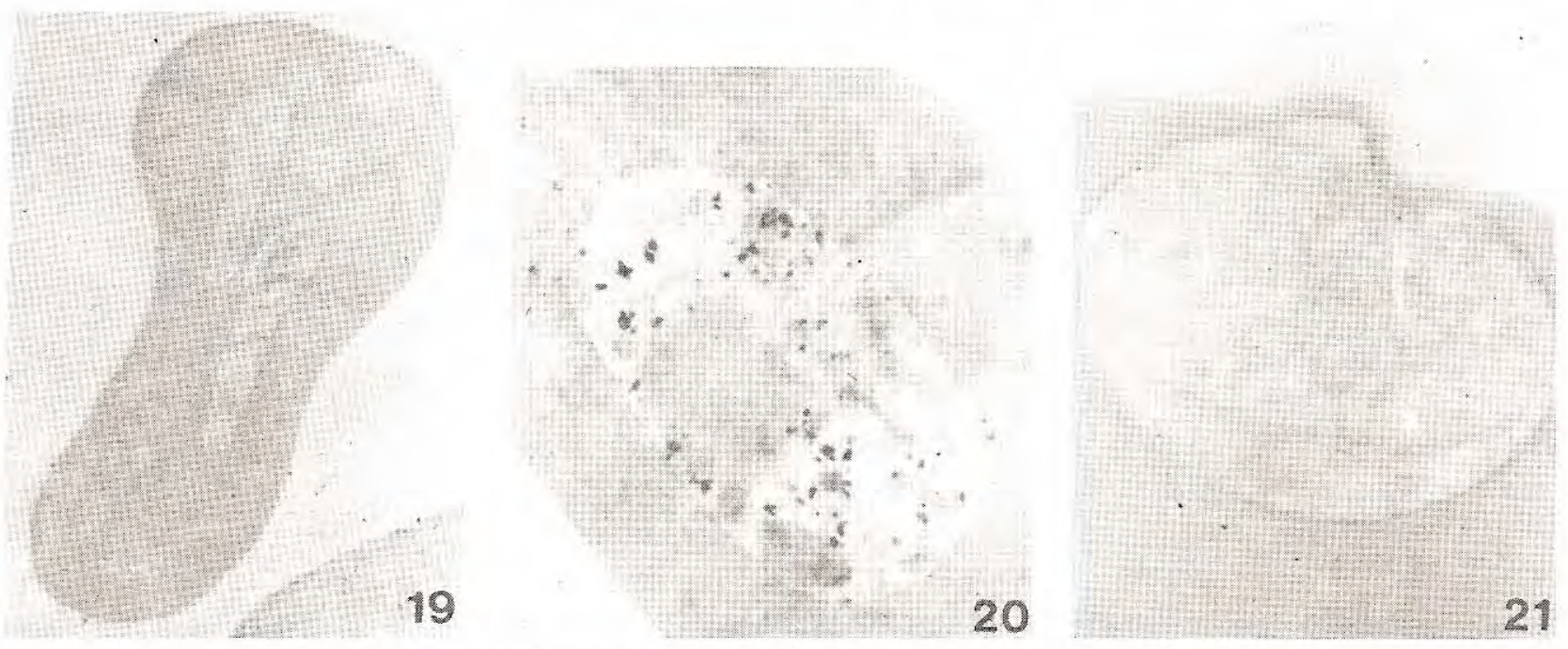

Figura 19. Inhibición de actividad de ATPasa de $\mathrm{Ca}^{2+}$ en un eritrocito invadido con anillos de 16-18 horas, con trifluoperazina $300 \mu \mathrm{M} 19200 \mathrm{X}$.

Figura 20. Inhibición de actividad de ATPasa de $\mathrm{Ca}^{2+}$ en un eritrocito invadido con anillos de 16-18 horas, con calmidazolium $300 \mu \mathrm{M} 45000 \mathrm{X}$.

Figura 21.Inhibición de actividad de ATPasa de $\mathrm{Ca}^{2+}$ en un eritrocito invadido con anillos de 16-18 horas, con cloruro de lantano $100 \mu \mathrm{M}$ 18000X. 
escogidas como ideales permitieron preservar tanto la morfología de las células como la actividad enzimática membranal de las mismas.

El método que usa fosfato de plomo como producto final de reacción citoquímica, con los ajustes de aumento de concentración de calcio dado por el ionóforo y la mayor permeabilidad de ATP hacia los sistemas membranales internos dada por la alameticina, es el método con resultados más satisfactorios para la demostración de actividad de ATPasa de calcio en células rojas invadidas por $P$ falciparum.

La caracterización de la actividad de ATPasa de calcio en este modelo, fue fundamental teniendo en cuenta que el eritrocito recién parasitado posiblemente necesita una salida más activa de calcio dado el incremento que se ha reportado (14) y que aparentemente sólo tiene este sistema activo para administrar la concentración intracelular de calcio $(4,11,15)$.

\section{Referencias}

1. Wasserman M, Crosby JA, Arreaza G. Estudios de invasión del parásitoPlasmodium falciparum a fantasmas de eritrocitos humanos. Rev Acad Col Ci Exac Fis 1989; 17:51-59.

2. Mendoza P. Efecto del $\mathrm{Ca}^{2+}$ sobre la invasión del $P$. falciparum a los eritrocitos humanos. Bogotá: Universidad Nacional de Colombia, Departamento de Química, 1987: 103. (Tesis Magister Scientiae en Química).

3. Strehler EE. Plasma membrane $\mathrm{Ca}^{2+}$ pumps and $\mathrm{Na}^{+} / \mathrm{Ca}^{2+}$ exchangers. Cell Biology 1990; seminars 1:283-295.
4. Carafoli E, et al. The calcium-transporting ATPase of erythrocytes. Ann N Y Acad Sci 1982;402:304-328.

5. Lewis PR, Knight DP. Staining methods for sectioned material. In: Glauert AM. Practical methods in electron microscopy. Amnsterdan: North-Holland Publishing Company, 1977:137-223.

6. Essner E. Phosphatases. In: Hayat MA. Electron Microscopy of enzymes. Voll. Principles and Methods. NewYork: Van Nostrand Reinhol Co., 1973:44-76.

7. Trager $\mathbf{W}$, Jensen J. Human malaria parasites in continuos culture. Science 1976;193:673-675.

8. De Rojas MO, Wasserman M. Supersincronización del crecimiento in vitro del Plasmodium falciparum. Biomédica 1987;7:75-80.

9. Rivadeneira EM, Wasserman M, Espinal C. Separation and concentration of schizonts of Plasmodium falciparum by percoll gradients. J Protozool 1983;30:367-370.

10. Sabatini DD, Bensch K, Barrnett RJ. Cytochemistry and electron microscopy. The preservation of cellular ultrastructure and enzymatic activity by Aldehyde fixation. $J$ Cell Biol 1963;17:19-58.

11. Sarkadi B, et al. The function and regulation of the calcium pump in the erythrocyte membrane.Ann NYAcad Sci 1982;402: 329-348.

12. Kirkpatrick FH, Hillman DG, La Celle PL. A23187 and red cells: changes in deformability, $\mathrm{K}^{+}, \mathrm{Mg}^{2+}, \mathrm{Ca}^{2+}$ andATP. Experientia 1975;31:653-654.

13. Lanners HN. Ultrastructure of erythrocytes from Aotus trivirgatus and Saimiri sciureus monkeys infected by Plasmodium vivax. Parasitol Res 1991;77:395-401.

14. Wasserman M, Vernot JP, Mendoza P. Role of calcium and erythrocyte cytoskeleton phosphorylation in the invasion of Plasmodium falciparum. Parasitol Res 1990;76: 681- 688.

15. Penniston JT. Plasma membrane $\mathrm{Ca}^{2+}$-pumping ATPases. Ann N Y Acad Sci 1982;402:297-303. 